\title{
Mobile phone radiation causes brain tumors and should be classified as a probable human carcinogen (2A) (Review)
}

\author{
L. LLOYD MORGAN ${ }^{1}$, ANTHONY B. MILLER ${ }^{2}$, ANNIE SASCO $^{3}$ and DEVRA LEE DAVIS ${ }^{1}$ \\ ${ }^{1}$ Environmental Health Trust, Teton Village, WY 83025, USA; ${ }^{2}$ Dalla Lana School of \\ Public Health, University of Toronto, Toronto, ON M4N 3P7, Canada; ${ }^{3}$ INSERM, ISPED, \\ Centre INSERM U897-Epidémiologie-Biostatistique, F-33000 Bordeaux, France
}

Received December 27, 2014; Accepted February 5, 2015

DOI: 10.3892/ijo.2015.2908

\begin{abstract}
Quickly changing technologies and intensive uses of radiofrequency electromagnetic field (RF-EMF)-emitting phones pose a challenge to public health. Mobile phone users and uses and exposures to other wireless transmitting devices (WTDs) have increased in the past few years. We consider that CERENAT, a French national study, provides an important addition to the literature evaluating the use of mobile phones and risk of brain tumors. The CERENAT finding of increased risk of glioma is consistent with studies that evaluated use of mobile phones for a decade or longer and corroborate those that have shown a risk of meningioma from mobile phone use. In CERENAT, exposure to RF-EMF from digitally enhanced cordless telephones (DECTs), used by over half the population of France during the period of this study, was not evaluated. If exposures to DECT phones could have been taken into account, the risks of glioma from mobile phone use in CERENAT are likely to be higher than published. We conclude that radiofrequency fields should be classified as a Group 2A 'probable' human carcinogen under the criteria used by the International Agency for Research on Cancer (Lyon, France). Additional data should be gathered on exposures to mobile and cordless phones, other WTDs, mobile phone base stations and $\mathrm{Wi}-\mathrm{Fi}$ routers to evaluate their impact on public health. We advise that the as low as reasonable achievable (ALARA) principle be adopted for uses of this technology, while a major cross-disciplinary effort is generated to train researchers in bioelectromagnetics and provide monitoring of potential health impacts of RF-EMF.
\end{abstract}

Correspondence to: Dr Anthony B. Miller, Dalla Lana School of Public Health, University of Toronto, 3800 Yonge Street, Suite 406, Toronto, ON M4N 3P7, Canada

E-mail: ab.miller@sympatico.ca

Key words: brain cancer, carcinogen, precautionary principle, radiofrequency fields

\section{Contents}

1. Introduction

2. The CERENAT study

3. Underestimation of risk of glioma in CERENAT and INTERPHONE

4. Meningioma elevated risk in CERENAT

5. Evidence that electromagnetic radiation can act both as an initiator and a promoter of tumors

6. Discussion

7. Conclusions

\section{Introduction}

In a world where the growth of mobile phone use and other wireless transmitting devices (WTDs) is without precedence, the issue of brain cancer and radiation from mobile phones has received considerable attention in the research community and by the general public. Occupational studies and studies of atomic bomb survivors indicate that the latency for brain cancer could be as long as three decades or more. The first reports on case-control studies published on this association in the 1990s lacked sufficient power to find an effect, because they studied persons who had used early technology (1 and $2 \mathrm{G})$ phones for relatively limited periods of time (1-4). The definition of 'regular use' (at least once a week, for 6 months or more) during a period of rapidly increasing mobile phone use resulted in an average use time of $\sim 6$ years. Both the INTERPHONE Study Group (5), and Coureau et al (6) used this definition of 'regular use.'

In the past few years a number of investigations have included those who have used phones for a decade or longer. In this report we identify and evaluate all case-control studies that incorporate decade-long use of mobile phones to provide a more complete picture of their potential impacts on public health.

ORs for the highest cumulative hours of exposure for brain cancer, glioma and acoustic neuroma are doubled or greater (range, 1.82-2.89) (Table I). Of particular interest are studies from Sweden and Korea. In the Korean study, significant increases for acoustic neuroma occurred with $>2,000$ cumulative hours of use when compared to less (7), and in 
the Swedish study for $>2,300 \mathrm{~h}$ of cumulative use (8). In three studies, increased risks for meningioma were also found at the highest cumulative hours of use $(5,6,9)$.

At the highest years of use there were significant risks for glioma $(5,10)$, brain cancer $(8)$ and acoustic neuroma $(11,12)$. For studies with greater years of use, acoustic neuroma tumor volume increased compared to less years of use $(7,12)$.

\section{The CERENAT study}

This French case-control study of cases $\geq 16$ years of age diagnosed between June 2004 and May 2006 included 253 glioma and 194 meningioma cases with two age- and gender-matched controls per case selected between 2005 and 2008 (6).

Potential confounders considered were the level of education, smoking, alcohol consumption, and occupational exposures to pesticides, extremely low frequency electromagnetic fields (ELF-EMF), radiofrequency electromagnetic fields (RF-EMFs), and ionizing radiation. In spite of listing RF-EMF as a potential confounder, separate analyses of exposures to digitally enhanced cordless telephones (DECTs) were not included, because questions about DECT use were not asked in the questionnaire.

During the period when cases were selected, the prevalence of French mobile phone use in 2004, 2005, and 2006 was 73, 78 , and $84 \%$ respectively, while the use of cordless phones is likely to have mirrored similar patterns of increasing use (13).

Risks of glioma were reported for 'heavy mobile phone use' ( $\geq 896$ cumulative hours of use) (Fig. 1). When 'heavy mobile phone use' was examined by years since first use, glioma risk increased from $>1$ year since first use, to $>2$ years, and to $>5$ years, OR 2.89, [95\% confidence interval (CI) 1.41-5.93], OR 3.03, (95\% CI 1.47-6.26), and OR 5.30, (95\% CI 2.12-13.23), respectively (6).

Risks were also reported by anatomical region. There was a borderline significant risk for glioma in the temporal lobe, OR 3.94 (95\% CI 0.81-19.08), which when combined with at least 5 years of use increased to a significantly elevated 5.3-fold risk; for frontal lobe tumors there was a non-significant increased risk, OR 1.87 (95\% CI 0.62-5.64), and for other regions a significant increased risk, OR 3.61 (95\% CI 1.00-12.96). Of the total mobile phone radiation absorbed by the brain, the temporal lobe absorbs 50-60\% and the frontal lobe absorbs 14-18\% (14).

The highest risk reported was among heavy mobile phone users from environments known to have multiple sources of WTDs at work and home in urban areas, OR 8.20 (95\% CI 1.37-49.07).

Higher risks were found from reported ipsilateral use, OR 2.11 (95\% CI 0.73-6.08) compared to contralateral use, OR 0.66 (95\% CI $0.23-1.89$ ).

The OR for analogue mobile phone use was 3.75 (95\% CI 0.97-14.43), that for digital mobile phone use was $2.71(95 \%$ CI 1.03-7.10). This is consistent with mobile phone use constituting a risk factor for glioma, because analogue mobile phones always radiated maximum power while the digital mobile phone's adaptive power control circuitry reduces the radiated power consistent with an acceptable signal to noise ratio.

For several exposure categories there was an increased risk with increased number of hours or calls per day of exposure: 'average calling time per month (hours)', $\mathrm{p}=0.02$; 'average
Risk of glioma with $\geq 896$ cumulative hours of use

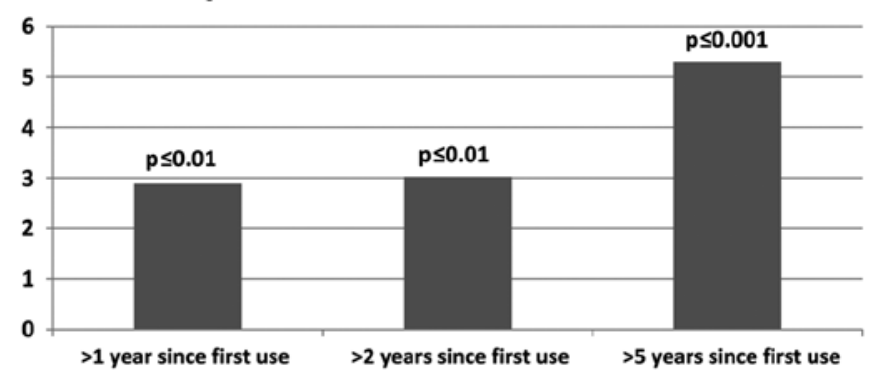

Figure 1. Risks among heavy mobile phone users with increasing years of use.

number of calls per day', $\mathrm{p}=0.04$; 'cumulative duration of call (hours)', $\mathrm{p}=0.02$.

Consistent with what is expected if there is a causal association between risks of glioma with different estimated exposure intensities, overall for $\geq 896$ cumulative hours of use ('heavy mobile phone use'), there was a significant 2.9 -fold increased risk.

\section{Underestimation of risk of glioma in CERENAT and INTERPHONE}

There are two principal reasons why the CERENAT findings as well as those of INTERPHONE are likely to have underestimated the risks of glioma from mobile phone use. First, exposures to RF-EMF radiation from conventional DECT can be substantial (15). Neither in INTERPHONE nor in CERENAT were these exposures evaluated. However Hardell et al $(8,12)$ reported risks of brain tumors from these devices similar to those from mobile phones. While in the CERENAT study RF-EMF exposures from other sources were listed as a potential confounder, questions were not asked about DECT use. Thus, the reference category 'no regular use' included subjects who used a DECT. This misclassification of exposure biases the findings towards the null.

Industry records reveal that the estimated prevalence of DECT use in France (introduced into France in 1992) was well above 50\% between 2004 and 2006.

A second factor that could contribute to an underestimation of risk is that the participation rate in CERENAT was relatively low: $66 \%$ for cases and $45 \%$ for controls (6). The 13-country INTERPHONE study's average participation rate was $70 \%$ for glioma, $79 \%$ for meningioma, $56 \%$ for controls (5). The authors of the INTERPHONE study acknowledged the possible selection bias from low participation rates and calculated that these resulted in a $10 \%$ underestimation of risk and the overall underestimation of glioma and meningioma risk was per 'the observed reductions below the null in the ORs in ever regular mobile phone users for meningioma $(21 \%, 95 \% \mathrm{CI}$ $32-9)$ and glioma (19\%, 95\% CI 30-6)' (5).

Hardell and Carlberg (16) suggested that the CERENAT method for analyzing laterality of risk was incorrect. In reply the CERENAT authors provided corrected calculations, showing that 'heavy' users incurred greater ipsilateral risks ( $\geq 896$ cumulative hours of use) (17) (Table II). By using the correction the OR for the highest cumulative hours of use for glioma doubled. 
Table I. Brain tumor risks in studies of decade-long mobile and cordless phone user metrics.

\begin{tabular}{|c|c|c|c|c|c|}
\hline & Studies (refs.) & Tumor & OR & $95 \% \mathrm{CI}$ & Comments \\
\hline $\begin{array}{l}\text { Cumulative hours } \\
\text { of use }\end{array}$ & & & & & $\begin{array}{l}\text { (DECT use not included } \\
\text { unless stated) }\end{array}$ \\
\hline $1,640+$ & $\begin{array}{l}\text { INTERPHONE Study } \\
\text { Group (5) }\end{array}$ & Glioma & 1.82 & $1.15-2.89$ & Ref. $<5$ cum. hours \\
\hline $1,640+$ & Hardell and Carlberg (21) & Glioma & 2.31 & $1.44-3.70$ & Includes DECT use \\
\hline$\geq 896$ & Coureau et al (6) & Glioma & 2.89 & $1.41-5.93$ & \\
\hline$>1,640$ & $\begin{array}{l}\text { INTERPHONE Study } \\
\text { Group (12) }\end{array}$ & Acoustic neuroma & 2.79 & $1.51-5.16$ & Exp. 5 years before ref. date \\
\hline$>1,486$ & & & 2.6 & $1.5-4.4$ & P-trend $=0.052$ \\
\hline Per $100 \mathrm{~h}$ & Hardell et al (8) & Acoustic neuroma & $10.3 \%$ & $2.4-18.7 \%$ & $>$ tumor size analogue phone \\
\hline$>2,000$ & Moon et al (7) & Acoustic neuroma & $8.8 \%$ & $2.3-15.7 \%$ & $>$ tumor size, ref. $<2,000 \mathrm{~h}$ \\
\hline$\geq 1,640$ & $\begin{array}{l}\text { INTERPHONE Study } \\
\text { Group (5) } \\
\text { INTERPHONE Study } \\
\text { Group (5) }\end{array}$ & Meningioma & 3.77 & $1.25-11.4$ & $\begin{array}{l}\text { Use for } 1-4 \text { years; } \\
\text { a promotion effect? } \\
\text { Use for } 1-4 \text { years; } \\
\text { a promotion effect? }\end{array}$ \\
\hline$>2,376$ & Carlberg et al (9) & Meningioma & 1.4 & $0.9-2.0$ & Includes DECT use \\
\hline$\geq 896$ & $\begin{array}{l}\text { Coureau et al (6) } \\
\text { Coureau et al (6) }\end{array}$ & $\begin{array}{l}\text { Meningioma } \\
\text { Glioma }\end{array}$ & $\begin{array}{l}2.57 \\
8.20\end{array}$ & $\begin{array}{l}1.02-6.44 \\
1.37-49.07\end{array}$ & Urban use only \\
\hline \multicolumn{6}{|l|}{ Years of use } \\
\hline $10+$ & $\begin{array}{l}\text { INTERPHONE Study } \\
\text { Group (5) }\end{array}$ & Glioma & 2.18 & $1.43-3.31$ & Ref. 1-1.9 years \\
\hline $10+$ & Hardell et al (10) & Glioma & 2.26 & $1.60-3.19$ & Includes DECT use \\
\hline$>5-10$ & Hardell et al (8) & Brain cancer & 1.7 & $0.98-2.8$ & For mobile phone, total \\
\hline$>25$ & Hardell et al (8) & Brain cancer & 2.9 & $1.4-5.8$ & \\
\hline$>5-10$ & Hardell et al (8) & Brain cancer & 2.3 & $1.6-2.3$ & \\
\hline$>20$ & Hardell et al (8) & Brain cancer & 4.5 & $2.1-9.5$ & \\
\hline Per year & Hardell et al (12) & Acoustic neuroma & $7.4 \%$ & $1.0-14.2 \%$ & $\begin{array}{l}\text { >tumor size } \\
\text { analogue phone }\end{array}$ \\
\hline$>10$ & Moon et al (7) & Acoustic neuroma & $4.5 \%$ & $-1.3-10.7 \%$ & $\begin{array}{l}>\text { tumor size } \\
\text { ref. }<10 \text { years }\end{array}$ \\
\hline \multicolumn{6}{|l|}{ Risk by age used } \\
\hline$<20$ years & Hardell and Carlberg (22) & Brain cancer & 7.8 & $2.2-28$ & $\begin{array}{l}\text { Mobile phone, }>1 \text { year, } \\
\text { ipsilateral use }\end{array}$ \\
\hline 20-29 years & Hardell and Carlberg (22) & Brain cancer & 2.1 & $1.5-2.9$ & $\begin{array}{l}\text { Mobile phone, }>1 \text { year, } \\
\text { ipsilateral use }\end{array}$ \\
\hline $50-80$ years & Hardell and Carlberg (22) & Brain cancer & 1.8 & $1.3-2.7$ & $\begin{array}{l}\text { Mobile phone, }>1 \text { year, } \\
\text { ipsilateral use }\end{array}$ \\
\hline
\end{tabular}

CI, confidence interval; DECT, digitally enhanced cordless telephone.

For glioma, all ipsilateral ORs were greater than contralateral ORs. With two exceptions, this was also true for meningioma. Because ipsilateral use results in higher exposure than contralateral, this is consistent what is expected if mobile phone use is a risk for glioma and meningioma.

\section{Meningioma elevated risk in CERENAT}

'Heavy mobile phone' use was associated with increased risks of meningioma (but somewhat weaker than the risks for glioma): for $>1$ year, OR 2.57 (95\% CI 1.02-6.44); for $>2$ years, OR 2.40 (95\% CI 0.96-6.05), and for $>5$ years (5 cases), OR 1.44 (95\% CI 0.43-4.80).

Risks were non-significantly elevated for temporal lobe (2 cases), OR 7.89 (95\% CI 0.48-130.14) and for frontal lobe (5 cases), OR 4.82 (95\% CI 0.78-29.63).

There was one significant and one borderline significant risk with increasing exposure: 'average calling time per month (hours)', $\mathrm{p}=0.04$; and 'cumulative duration of calls (hours)', $\mathrm{p}=0.06(6)$. 
Table II. Results for cumulative hours of use [adapted from Coureau et al (6) Appendix 2; corrected results adapted from Coureau et al (17)].

\begin{tabular}{|c|c|c|c|c|}
\hline \multirow[b]{2}{*}{ Exposures } & \multicolumn{2}{|c|}{ Glioma } & \multicolumn{2}{|c|}{ Meningioma } \\
\hline & $\begin{array}{c}\text { Ipsilateral }^{\mathrm{a}} \\
\text { OR }(95 \% \mathrm{CI})\end{array}$ & $\begin{array}{l}\text { Contralateral }^{\mathrm{b}} \\
\text { OR }(95 \% \mathrm{CI})\end{array}$ & $\begin{array}{c}\text { Ipsilateral }^{\mathrm{a}} \\
\text { OR }(95 \% \mathrm{CI})\end{array}$ & $\begin{array}{l}\text { Contralateral }{ }^{\mathrm{b}} \\
\text { OR }(95 \% \mathrm{CI})\end{array}$ \\
\hline
\end{tabular}

Cumulative hours

of use

\begin{tabular}{lcccc} 
Not regular use & Referent & Referent & Referent & Referent \\
$<43$ & $0.43(0.21-0.88)$ & $0.24(0.10-0.57)$ & $0.39(0.16-0.96)$ & $0.53(0.23-1.19$ \\
$43-112$ & $0.39(0.18-0.84)$ & $0.23(0.08-0.63)$ & $0.34(0.13-0.85)$ & $0.26(0.10-0.68)$ \\
$113-338$ & $0.87(0.43-1.75)$ & $0.13(0.04-0.44)$ & $0.03(0.01-0.25)$ & $0.39(0.17-0.92)$ \\
$339-895$ & $0.86(0.39-1.93)$ & $0.51(0.21-1.28)$ & $0.30(0.08-1.15)$ & No data \\
$\geq 896$ & $2.11(0.73-6.08)$ & $0.66(0.23-1.89)$ & $2.29(0.58-8.97)$ & $1.18(0.34-4.12)$ \\
Cumulative hours & & & & Referent \\
of use corrected & Referent & Referent & $0.99(0.34-2.90)$ \\
Not regular use & $0.29(0.11-.80)$ & $0.25(0.07-0.95)$ & $0.64(0.15-2.73)$ & $0.13(0.02-1.07)$ \\
$<43$ & $0.44(0.16-1.23)$ & $0.33(0.10-1.08)$ & $0.37(0.10-1.39)$ & $0.65(0.23-1.80)$ \\
$43-112$ & $0.78(0.27-2.24)$ & $0.25(0.06-1.02)$ & No data & No data \\
$113-338$ & $1.69(0.52-5.49)$ & $0.23(0.05-1.11)$ & $0.14(0.02-1.24)$ & $1.24(0.21-7.48)$ \\
$339-895$ & $4.21(0.70-25.52)$ & $1.61(0.36-7.14)$ & $2.27(0.42-12.39)$ & \\
$\geq 896$ & & & & \\
\hline
\end{tabular}

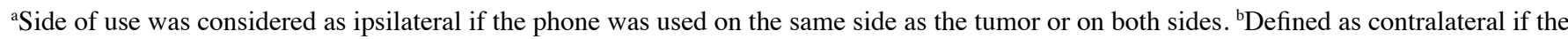
phone was used on the opposite side of the tumor. No laterality was assigned for median tumor. CI, confidence interval.

\section{Evidence that electromagnetic radiation can act both as an initiator and a promoter of tumors}

For an agent that initiates a tumor, a long time to detection is expected. Thus, brain tumors generally are believed to have a latency of a decade or more, ranging up to five decades in some studied populations. The average time (a statistical distribution) to diagnosis (latency) falls within an expected range of average times. In contrast, for an agent that acts at the later stages of carcinogenesis, an earlier diagnosis of already initiated tumors occurs (promotion).

With an average 2.9 years of mobile phone use Muscat et al (4) reported a borderline significant result for a rare brain cancer, OR 2.1 (95\% CI 0.9-4.7). Auvinen et al (1) reported a significant increased risk of glioma with $>2$ years of mobile phone use, OR 2.0, (95\% CI 1.0-4.1), with a dose-response increase in OR of 1.2/year (95\% CI 1.1-1.5).

The INTERPHONE Study Group (5) also found indications of promoting effects; the OR for glioma and meningioma with 1-4 years of use and for $>1,640$ cumulative hours of use was 3.77 (95\% CI 1.25-11.4) and 4.80 (95\% CI 1.49-15.4), respectively (Table I).

Hardell et al (18) also reported elevated risks with short-term use. For example, the OR for meningioma and acoustic neuroma with $<1-5$ years of digital mobile phone use for $>64 \mathrm{~h}$ was 1.8 (95\% CI 1.1-3.0) and 1.9 (95\% CI 0.7-4.7), respectively. Hardell and Carlberg (15) wrote '...ipsilateral exposure indicated an early effect in glioma development, which is an increased risk with long latency. However, we also found an increased risk with short latency, indicating a late effect in tumor development...these results could be compatible with both tumor initiation and promotion'. This is illustrated in Fig. 2.

\section{Discussion}

In reviewing the epidemiological evidence on mobile phone use and brain tumors, The IARC Monograph Working Group (19) noted the limited data available from epidemiological studies at that time though noting that Hardell et al have conducted the most detailed and largest number of studies on the risks for glioma from wireless phone (mobile and/or cordless phone).

Morgan et al (20) suggested that the magnitude of the under-estimation of risk was $25 \%$ in the INTERPHONE study. This is consistent with the INTERPHONE Study Group (5) conclusion that their under-estimation was at least $19 \%$ based on 'regular' mobile phone use. Nevertheless, when minimal use was defined as the reference level, risks in the INTERPHONE study were significant: for $10+$ years since first use compared to 1-1.9 years since first use, OR 2.18 (95\% CI 1.43-3.31), for $>1,640$ cumulative hours of use compared to $<5 \mathrm{~h}$ of use, OR 1.82 (95\% CI 1.15-2.80).

The IARC Monograph Working Group concluded that radiofrequency fields were possible human carcinogens, 
Table III. APC of GBM by brain increased glioma in three major cancer registries, 1992-2006 [adapted from Table III of Deltour et al (25)].

\begin{tabular}{|c|c|c|c|c|c|c|}
\hline \multirow[b]{2}{*}{ Brain region } & \multicolumn{2}{|c|}{ LAC } & \multicolumn{2}{|c|}{ CCR } & \multicolumn{2}{|c|}{ SEER 12} \\
\hline & $\operatorname{APC}(\%)$ & P-value & $\operatorname{APC}(\%)$ & P-value & APC $(\%)$ & P-value \\
\hline Frontal & +3.0 & 0.001 & +2.4 & $<0.001$ & +2.5 & $<0.001$ \\
\hline Temporal & +2.0 & 0.010 & +1.9 & 0.026 & +1.3 & 0.027 \\
\hline Cerebellum & N/A & N/A & +11.9 & $<0.001$ & +1.6 & NS \\
\hline
\end{tabular}

APC, annual percent change; GBM, glioblastoma multiforme; LAC, Los Angeles County; CCR, California Cancer Registry; N/A, not available; NS, not significant.

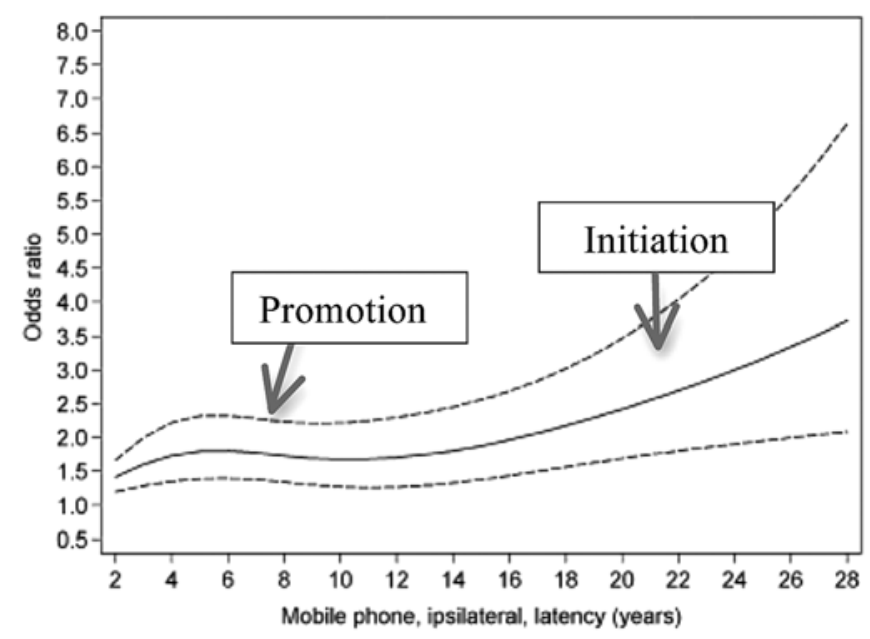

Figure 2. Findings of promotion and initiation in long-term case-control studies of glioma and mobile phone radiation. Adapted from Fig. 3 in Hardell and Calberg (16). This displays a cubic spline result with a solid line indicating the OR estimate and the broken lines represent the $95 \%$ confidence interval (CI)

Group 2B (19). Since then, a number of studies have been published of experimental results showing that radiofrequency fields affect cellular repair and increase biomarkers associated with cancer risk. In our view these results and several epidemiology studies $(8,21)$ are consistent with what is expected if radiofrequency fields from mobile phone use are a cause of brain cancer: the higher the cumulative hours of use, the higher the risk; the longer the time since first use, the higher the risk; the higher the radiated power, the higher the risk; ipsilateral risk is higher than contralateral risk.

Thus, evidence published since the IARC review provides additional support, based on IARC criteria, for concluding that radiofrequency fields are probable human carcinogens; radiofrequency fields should now be classified Group 2A.

At the time of the IARC review it was known that when mobile phone use began as a teenager, the risks were higher than when use began as an adult $(22,23)$. Since then, additional evidence has accrued of an increased risk to children. In the CEFALO study, using operator reported data, an OR of 2.15 (95\% CI 1.06-4.29) was reported for children of median age 13 with $>2.8$ years since time from first subscription, combined with an increasing risk with increase in years since first use,
P-trend $=0.001$ (24). In addition, the CEFALO authors reported an ipsilateral risk with $>4$ years of cumulative duration of subscriptions, OR 3.74 (95\% CI 1.19-11.77) in combination of an increasing risk with increasing years of use, P-trend $=0.02$.

As the young adult brain is not fully myelinated, and wireless radiation has been shown to induce demyelination experimentally, it is plausible that wireless radiation could have a stronger impact on the developing brain than on older adults.

It has been suggested that if mobile phone use was causing brain cancer, with so many people using mobile phones there should be an increase in brain cancer, but there has been none $(25,26)$. This is not correct.

Recently a significant annual percent change (APC) in age-adjusted rates of brain cancer between 1992 and 2006 was reported from the United States using data from three cancer registries: Los Angeles County (LAC), California Cancer Registry (CCR), and the SEER 12 cancer registry (27). Table III shows this increase in brain cancer for the three anatomical regions that absorb the greatest proportion of the absorbed mobile phone radiation in the brain $(81 \%$ at $900 \mathrm{MHz}$ and $86 \%$ at $1,800 \mathrm{MHz}$ ) (14).

Also showing incidence increases is an Australian study of regional hospital-based data for the years 2000-2008. Dobes et al (28) stated, 'a significant increasing incidence in glioblastoma multiforme (GBM) was observed in the study period (APC 2.5; 95\% CI 0.4\%-4.6, n=2,275), particularly after 2006'.

An increasing incidence of brain tumors during 2003-2012, $41.2 \%$ among men and $46.1 \%$ in women has been noted in Denmark, cases of GBM nearly doubled in the previous 10 years (29).

The case-control design is generally considered the preferred methodology for studying brain cancer risk tied with mobile phone use, as with any relatively rare disease with extensive exposure. The latency reported between known causes of brain cancer and development of the disease appears to range from 10 to 50 years. Because brain cancer is a relatively rare disease with a relatively long latency, and the reported relative risk associated with mobile phone use thus far ranges from 1.5 to 8 , in order to have sufficient power to detect a real increase in risk associated with mobile phone use, prospective cohort studies would have to include $>3$ million persons followed for 20 years to have $80 \%$ power. 
A retrospective cohort study of $\sim 400,000$ cell phone users in Denmark has been reported evaluating brain cancer risk in persons who began using cell phones in 1992-1994 compared to those who began to use cell phones later (30). The authors excluded business users from the exposed contending they were unable to know if a phone registered to a business user was solely used by that person, including these same business users in the unexposed category. This misclassification of exposure impairs the ability of the study to detect an increase in risk, while it lacks statistical power, as it involves a small cohort for which exposure information has not been updated for 20 years.

\section{Conclusions}

The CERENAT study corroborates the significant risks of glioma associated with exposure to radiofrequency fields reported by the Swedish team and by the 13-country INTERPHONE study, and adds weight to the epidemiological evidence that radiofrequency fields, classified by the International Agency for Research on Cancer as a Group 2B (possible) carcinogen in 2011 should be reclassified as a Group 2A (probable) carcinogen.

In the CERENAT study, a significant increased risk of brain cancer was found from mobile phone use overall with an 8 -fold increased risk for higher urban exposures. Three out of every four persons today live in mega-cities with populations of $>10$ million, many in the rapidly developing world where exposures to RF-EMF may be poorly controlled and access to medical treatment problematic. CERENAT also corroborates those few studies that have shown a risk of meningioma from mobile phone use.

The growth of mobile phone use worldwide has reached the level that in many nations there are more phones than adults. Exposures today can occur simultaneously from a number of WTDs such as mobile phones, mobile phone base stations (as known as masts or cell towers), and tablets, with the latter often being held quite close to the bodies of users (ignoring that the exposure limit is measured at $20 \mathrm{~cm}$ distance from tablets, laptop computer, and similar WTDs).

Until further evidence is available, it is prudent for policies about the use and development of WTDs rely on reducing exposures to the ALARA standard used in pediatric radiology. The ALARA approach would require hardware and software designers to create proximity sensors and embed flash notices regarding simple advisories about safer use within devices. In the meantime, we urge that serious national programs of training and research be established to train experts in evaluating this technology and establish appropriate monitoring and surveillance systems such as those in place for pharmaceuticals and other agents. This program could be funded by a fee of 2 cents/month to be paid equally from consumers, manufacturers, and providers into an independently operated research and training program.

\section{Acknowledgements}

We wish to thank Barb Payne for her great proofreading skills and the Environmental Health Trust, a non-profit research and policy institution, for supporting this effort.

\section{References}

1. Auvinen A, Hietanen M, Luukkonen R and Koskela RS: Brain tumors and salivary gland cancers among cellular telephone users. Epidemiology 13: 356-359, 2002.

2. Christensen HC, Schüz J, Kosteljanetz M, Poulsen HS, Boice JD Jr, McLaughlin JK and Johansen C: Cellular telephones and risk for brain tumors: A population-based, incident case-control study. Neurology 64: 1189-1195, 2005.

3. Inskip PD, Tarone RE, Hatch EE, Wilcosky TC, Shapiro WR, Selker RG, Fine HA, Black PM, Loeffler JS and Linet MS: Cellular-telephone use and brain tumors. N Engl J Med 344: 79-86, 2001.

4. Muscat JE, Malkin MG, Thompson S, Shore RE, Stellman SD, McRee D, Neugut AI and Wynder EL: Handheld cellular telephone use and risk of brain cancer. JAMA 284: 3001-3007, 2000. Erratum in: JAMA 286: 1293, 2001.

5. INTERPHONE Study Group: Brain tumour risk in relation to mobile telephone use: Results of the INTERPHONE international case-control study. Int J Epidemiol 39: 675-694, 2010.

6. Coureau G, Bouvier G, Lebailly P, et al: Mobile phone use and brain tumours in the CERENAT case-control study. Occup Environ Med 71: 514-522, 2014.

7. Moon IS, Kim BG, Kim J, Lee JD and Lee WS: Association between vestibular schwannomas and mobile phone use. Tumour Biol 35: 581-587, 2014.

8. Hardell L, Carlberg M, Söderqvist F and Mild KH: Pooled analysis of case-control studies on acoustic neuroma diagnosed 1997-2003 and 2007-2009 and use of mobile and cordless phones. Int J Oncol 43: 1036-1044, 2013

9. Carlberg M, Söderqvist F, Hansson Mild K and Hardell L: Meningioma patients diagnosed 2007-2009 and the association with use of mobile and cordless phones: A case-control study. Environ Health 12: 60, 2013.

10. Hardell L, Carlberg M and Hansson Mild K: Re-analysis of risk for glioma in relation to mobile telephone use: Comparison with the results of the Interphone international case-control study. Int J Epidemiol 40: 1126-1128, 2011.

11. INTERPHONE Study Group: Acoustic neuroma risk in relation to mobile telephone use: Results of the INTERPHONE international case-control study. Cancer Epidemiol 35: 453-464, 2011.

12. Hardell L, Carlberg M, Söderqvist F and Mild KH: Pooled analysis of case-control studies on acoustic neuroma diagnosed 1997-2003 and 2007-2009 and use of mobile and cordless phones. Int J Oncol 43: 1036-1044, 2013.

13. The World Bank: Mobile cellular subscriptions (per 100 people). http://data.worldbank.org/indicator/IT.CEL.SETS. P2?order=wbapi_data_value_2006 wbapi_data_value\&sort= asc\&page $=1$. Accessed September 19, 2014.

14. Cardis E, Deltour I, Mann S, Moissonnier M, Taki M, Varsier N, Wake K and Wiart J: Distribution of RF energy emitted by mobile phones in anatomical structures of the brain. Phys Med Biol 53: 2771-2783, 2008

15. Hardlell $\mathrm{L}$ and Carlberg M: Mobile phone and cordless phone use and the risk for glioma - Analysis of pooled case-control studies in Sweden, 1997-2003 and 2007-2009. Pathophysiology: Oct 29, 2014 (Epub ahead of print).

16. Hardell L and Carlberg M: Re: Mobile phone use and brain tumours in the CERENAT case-control study. Occup Environ Med 72: 79, 2015.

17. Coureau G, Leffondre K, Gruber A, Bouvier G and Baldi I: Author's response: $\mathrm{Re}$ 'Mobile phone use and brain tumours in the CERENAT case-control study'. Occup Environ Med 72: 79-80, 2015.

18. Hardell L, Carlberg M and Hansson Mild K: Case-control study on cellular and cordless telephones and the risk for acoustic neuroma or meningioma in patients diagnosed 2000-2003. Neuroepidemiology 25: 120-128, 2005.

19. International Agency for Research on Cancer (IARC): Nonionizing radiation, part 2: radiofrequency electromagnetic fields. IARC Monographs on the Evaluation of Carcinogenic Risks to Humans. Volume 102. IARC, Lyon, 2013.

20. Morgan LL, Kundi M and Carlberg M: Re-evaluation of the Interphone Study: Application of a correction factor. In: Proceedings of the Bioelectromagnetics Society Annual Meeting. Seoul, Korea, pp1-7, 2010.

21. Hardell L and Carlberg M: Using the Hill viewpoints from 1965 for evaluating strengths of evidence of the risk for brain tumors associated with use of mobile and cordless phones. Rev Environ Health 28: 97-106, 2013. 
22. Hardell L and Carlberg M: Mobile phones, cordless phones and the risk for brain tumours. Int J Oncol 35: 5-17, 2009.

23. Hardell L, Carlberg M and Hansson Mild K: Pooled analysis of two case-control studies on the use of cellular and cordless telephones and the risk of benign brain tumours diagnosed during 1997-2003. Int J Oncol 28: 509-518, 2006.

24. Aydin D, Feychting M, Schüz J, et al: Mobile phone use and brain tumors in children and adolescents: A multicenter case-control study. J Natl Cancer Inst 103: 1264-1276, 2011.

25. Deltour I, Auvinen A, Feychting M, Johansen C, Klaeboe L, Sankila R and Schüz J: Mobile phone use and incidence of glioma in the Nordic countries 1979-2008: Consistency check. Epidemiology 23: 301-307, 2012.

26. Little MP, Rajaraman P, Curtis RE, Devesa SS, Inskip PD, Check DP and Linet MS: Mobile phone use and glioma risk: Comparison of epidemiological study results with incidence trends in the United States. BMJ 344: e1147, 2012.
27. Zada G, Bond AE, Wang YP, Giannotta SL and Deapen D: Incidence trends in the anatomic location of primary malignant brain tumors in the United States: 1992-2006. World Neurosurg 77: 518-524, 2012

28. Dobes M, Khurana VG, Shadbolt B, Jain S, Smith SF, Smee R, Dexter $\mathrm{M}$ and Cook R: Increasing incidence of glioblastoma multiforme and meningioma, and decreasing incidence of Schwannoma (2000-2008): Findings of a multicenter Australian study. Surg Neurol Int 2: 176, 2011.

29. The Danish Cancer Society: The increase in new cases of aggressive brain cancer. http://www.cancer.dk/Nyheder/nyhedsartikler/2012kv4/Kraftigstigningihjernesvulster.html. Accessed September 22, 2014

30. Schüz J, Jacobsen R, Olsen JH, Boice JD Jr, McLaughlin JK and Johansen C: Cellular telephone use and cancer risk: Update of a nationwide Danish cohort. J Natl Cancer Inst 98: 1707-1713, 2006. 